\title{
ENKELE NADERE GEGEVENS BETREFFENDE DEN „CURSUS H.B.S. B” TE PARAMARIBO OVER DE PERIODE VAN ZIJN BESTAAN
}

\author{
gepubliceerd door P. WAGENAAR HUMMELINCK
}

Het bestaan van een „Cursus H.B.S. B” (Algemeen Middelbare School) te Paramaribo, van 1 November 1943 tot 31 Mei 1946 waarover in het artikel van prof. dr A.B. DROOGLEEvER ForTUYN over ,Middelbaar Onderwijs in Suriname” verslag werd gedaan (W. I. Gids jrg. $28 \mathrm{dl} \mathrm{29,} \mathrm{blz.} \mathrm{97-106)} \mathrm{-} \mathrm{lijkt} \mathrm{mij} \mathrm{van} \mathrm{zoo} \mathrm{groote}$ beteekenis voor het cultureele leven in Suriname, dat ik niet kan nalaten - mede met het oog op de geschiedschrijving van dit land - enkele gegevens te publiceeren uit het feitenmateriaal dat mij, op mijn verzoek, door ir J. E. HeEsterman ter inzage werd gegeven.

1. Lijst vandocenten.

\begin{tabular}{|c|c|c|}
\hline Naam & Bevoegdheid, diploma & Gegeven lessen \\
\hline $\begin{array}{l}\text { Hevi.C.E. DRo'ogleEver } \\
\text { ForTUYN-vAN LEYDEN }\end{array}$ & Biologisch doctoranda. & $\begin{array}{l}\text { Plant- en Dierkunde; } \\
\text { volgde dr Geijskes op na } \\
\text { vertrek met verlof. }\end{array}$ \\
\hline Mej.J. Essed & Hoofdacte L.O. & $\begin{array}{l}\text { Nederlandsch; volgde } \\
\text { mevr. Jessurun op na } \\
\text { vertrek. }\end{array}$ \\
\hline Mej. A. Groenewegen & Acte Duitsch M.O. A & Duitsch. \\
\hline $\begin{array}{l}\text { Mevr. dr S. C. Jessurun- } \\
\text { TEN DAM HAM }\end{array}$ & $\begin{array}{l}\text { M.O. bevoegdheid Neder- } \\
\text { landsch, Geschiedenis, } \\
\text { Staatsinrichting, Staat- } \\
\text { huishoudkunde. }\end{array}$ & $\begin{array}{l}\text { Nederlandsch, ook Ge- } \\
\text { schiedenisgedurendever- } \\
\text { lof dr Einaar. }\end{array}$ \\
\hline Mej. J. Thомson & Acte Fransch M.O. A & Fransch. \\
\hline R. ANIJS & Acte Gymnastiek L.O. & Lichamelijke Oefening. \\
\hline H. A. J. BAttAERD & Chemisch candidaat. & $\begin{array}{l}\text { Scheikunde, klasse II cur- } \\
\text { sus } 1944-1945 .\end{array}$ \\
\hline C. R. Biswamitre & $\begin{array}{l}\text { Acte Staatsinrichting } \\
\text { M.O. }\end{array}$ & Staatsinrichting. \\
\hline W. Bos Verschuur & Acte teekenen M.A. & $\begin{array}{l}\text { Handteekenen en Recht- } \\
\text { lijnig Teekenen. }\end{array}$ \\
\hline A. T. CALOR & Hoofdacte L.O. & $\begin{array}{l}\text { Aardrijkskunde en Kos- } \\
\text { mografie. }\end{array}$ \\
\hline
\end{tabular}




\begin{tabular}{|c|c|c|}
\hline Naam & Bevoegdheid, diploma & Gegeven lessen \\
\hline Dr J. F. E. EINAAR & $\begin{array}{l}\text { M.O. bevoegdheid ge- } \\
\text { schiedenis. }\end{array}$ & Geschiedenis. \\
\hline Ir H. DE GEUS & $\begin{array}{l}\text { Electrotechnisch inge- } \\
\text { nieur. }\end{array}$ & Mechanica. \\
\hline Dr D. C. GeIJS Kes & M.O. bevoegdheid biologie & Plant- en Dierkunde. \\
\hline C. G. Getrouw & Hoofdacte L.O. & $\begin{array}{l}\text { Geschiedenis; volgde } \\
\text { mevr. Jessurun op na } \\
\text { vertrek. }\end{array}$ \\
\hline Ir J. E. Heesterman & Chemisch ingenieur. & $\begin{array}{l}\text { Natuurkunde, gedurende } \\
\text { een deel van de cursus } \\
\text { ook scheikunde. (D i- } \\
\text { r e t e u r). }\end{array}$ \\
\hline H. J. HEILBRoN & Hoofdacte L.O. & $\begin{array}{l}\text { Aardrijkskunde; verving } \\
\text { tijdelijk den heer Calor } \\
\text { gedurende verlof. }\end{array}$ \\
\hline Dr H. J. MUULER & $\begin{array}{l}\text { M.O. bevoegdheid schei- } \\
\text { kunde. }\end{array}$ & Scheikunde. \\
\hline L. J. Smit & Acte Fransch L.O. & $\begin{array}{l}\text { Fransch; volgde mej. } \\
\text { Thomson op na vertrek } \\
\text { met verlof. }\end{array}$ \\
\hline W. SMIt & Acte Boekhouden M.O. & $\begin{array}{l}\text { Handelswetenschappenen } \\
\text { Staathuishoudkunde. }\end{array}$ \\
\hline H. SNo & Acte Wiskunde $\mathrm{K} 1$. & Wiskunde. \\
\hline
\end{tabular}

2. Overzicht over het leerlingenaantal.

Aantal leerlingen per klasse a bij begin van cursusjaar

b aan einde van cursusjaar

c gemiddeld gedurende cursusjaar

\begin{tabular}{|c|c|c|c|}
\hline & Klasse I & Klasse II & Klasse III \\
\hline Cursus 1943-1944 . . . . . . & $\begin{array}{ll}\text { a } & 24 \\
\text { b } & 16 \\
\text { c } & 20,9\end{array}$ & & \\
\hline Cursus 1944-1945 . . . . . . & $\begin{array}{ll}\text { a } & 27 \\
\text { b } & 21 \\
\text { c } & 23,9\end{array}$ & $\begin{array}{ll}\text { a } & 11 \\
\text { b } & 10 \\
\text { c } & 10,2\end{array}$ & \\
\hline Cursus 1945-1946 . . . . . . & & $\begin{array}{lc}\text { a } & 12 \\
\text { b } & 4 \\
\text { c } & 7,9\end{array}$ & $\begin{array}{ll}\mathrm{a} & 5 \\
\mathrm{~b} & 4 \\
\mathrm{c} & 4,6\end{array}$ \\
\hline
\end{tabular}

3. Ontvangen Gouvernementssubsidies.

Over cursusjaar 1943-1944. . . . . . . . . . . . . $f$ 3290,-

Over cursusjaar 1944-1945. . . . . . . . . . . . . . f 3408,- 
4. Lesrooster ingaande 1 Mei 1945.

ES beteekent Emmastraat HS beteekent Hendrikschool Hstr beteekent Heerenstraat ST beteekent Sportterrein

\begin{tabular}{|c|c|c|c|c|c|}
\hline \multirow{2}{*}{ Dag } & \multirow{2}{*}{ Tijd } & \multicolumn{2}{|l|}{ Klasse I } & \multicolumn{2}{|l|}{ Klasse II } \\
\hline & & Vak & Plaats & Vak & Plaat \\
\hline \multirow[t]{9}{*}{ Maandag } & $7.00-7.50$ & & & Scheikunde & HS \\
\hline & $7.55-8.45$ & & & Teekenen & HS \\
\hline & $8.50-9.40$ & Scheikunde & ES & Teekenen & HS \\
\hline & $9.45-10.35$ & Mechanica & ES & Wiskunde & Hstr \\
\hline & $10.40-11.30$ & Fransch & ES & Engelsch & Hstr \\
\hline & $11.30-13.00$ & Duitsch & ES & & \\
\hline & $15.30-16.20$ & Engelsch & ES & Wiskunde & Hstr \\
\hline & $16.25-17.15$ & Natuurkunde & ES & Duitsch & Hstr \\
\hline & $17.20-18.10$ & Duitsch & ES & Natuurkunde & Hstr \\
\hline \multirow[t]{8}{*}{ Dinsdag } & $7.00-7.50$ & & & Natuurl. Hist. & ES \\
\hline & $7.55-8.45$ & Natuurl. Hist. & ES & Geschiedenis & Hstr \\
\hline & $8.50-9.40$ & Scheikunde & ES & Nederlandsch & Hstr \\
\hline & $9.45-10.35$ & Nederlandsch & ES & Handelswetensch. & Hstr \\
\hline & $10.40-11.30$ & Fransch & ES & & \\
\hline & $15.30-16.20$ & Wiskunde & ES & Fransch & HS \\
\hline & $16.25-17.15$ & Lich. Oef. & HS & Aardrijkskunde & HS \\
\hline & $17.20-18.10$ & Aardrijkskunde & HS & Lich. Oef. & HS \\
\hline \multirow[t]{8}{*}{ Woensdag } & $7.00-7.50$ & Natuurkunde & ES & & \\
\hline & $7.55-8.45$ & Teekenen & HS & Natuurkunde & ES \\
\hline & $8.50-9.40$ & Teekenen & HS & Staatshuishoudk. & ES \\
\hline & $9.45-10.35$ & Staathuishoudk. & ES & Wiskunde & HS \\
\hline & $10.40-11.30$ & Wiskunde & ES & Fransch & Hstr \\
\hline & $15.30-16.20$ & Wiskunde & ES & Engelsch & Hstr \\
\hline & $16.25-17.15$ & Engelsch & ES & Scheikunde & Hstr \\
\hline & $17.20-18.10$ & Geschiedenis & ES & Natuurkunde & Hstr \\
\hline \multirow[t]{7}{*}{ Donderdag } & $7.00-7.50$ & & & Natuurl. Hist. & SE \\
\hline & $7.55-8.45$ & Natuurl. Hist. & ES & Geschiedenis & Hstr \\
\hline & $8.50-9.40$ & Aardrijkskunde & ES & Nederlandsch & Hstr \\
\hline & $9.45-10.35$ & Nederlandsch & ES & Mechanica & Hstr \\
\hline & $10.40-11.30$ & Geschiedenis & ES & & \\
\hline & $15.30-16.20$ & & & Wiskunde & Hstr \\
\hline & $16.30-17.30$ & Lich. Oef. meisjes & eide & lassen & ST \\
\hline \multirow[t]{9}{*}{ Vrijdag } & $7.00-7.50$ & Scheikunde & ES & & \\
\hline & $7.55-8.45$ & Engelsch & ES & Aardrijkskunde & Hstr \\
\hline & $8.50-9.40$ & Nederlandsch & ES & Engelsch & Hstr \\
\hline & $9.45-10.35$ & Staatsinricht. & ES & Nederlandsch & Hstr \\
\hline & $10.40-11.30$ & Fransch & ES & Staatsinricht. & Hstr \\
\hline & $11.30-13.00$ & & & Duitsch & Hstr \\
\hline & $15.30-16.20$ & Wiskunde & ES & Scheikunde & HS \\
\hline & $16.25-17.15$ & Natuurkunde & ES & Fransch & HS \\
\hline & $17.20-18.10$ & & & Natuurkunde & ES \\
\hline \multirow[t]{3}{*}{ Zaterdag } & $7.30-8.20$ & Wiskunde & ES & Lich. & ST \\
\hline & $8.40-9.30$ & Lich. Oef. & ST & Wiskunde & ES \\
\hline & $9.40-10.30$ & Lich. Oef. meisjes & it beide $\mathrm{k}$ & klassen & HS \\
\hline
\end{tabular}


5. Prospectus over den ,H BS Cursus georganiseerd door de Vereeniging voor Middelbaar Onderwijs in Suriname".

(Een analoog prospectusje werd in 1943 verspreid. Interessant in verband met de kwestie van de achtergehouden requesten is het slot van het stukje over het diploma. Het bedoelde request, dat de opstellers in Londen waanden, sliep echter in de archieven van het Departement van Onderwijs te Paramaribo.)

NADERE VOORWAARDEN en BIJZONDERHEDEN van den cursus, aanvangende 1 November 1944.

Cursusgeld. Het cursusgeld bedraagt:

$f 240$,- - per jaar bij een jaarlijksch inkomen van ouders of verzorgers tot $f 5000$

$f 360$,- per jaar bij een jaarlijksch inkomen van ouders of verzorgers van $f 5001,-$ tot $f 10000$, -

$f 480$,- - per jaar bij een jaarlijksch inkomen van ouders of verzorgers boven $f 10000$,- .

Het cursusgeld wordt betaald in twaalf gelijke termijnen.

Bij den aanvang van elke maand, uiterlijk op den achtsten dier maand, moet telkens een termijn betaald worden, voor het eerst op uiterlijk 8 November 1944.

Schoolboeken. Daar gedrukte boeken voor het grootste deel niet te krijgen zijn, is het noodig gecyclostyleerde exemplaren te gebruiken. Het is noodig de aanschaffing hiervan coöperatief te doen voor alle leerlingen tegelijk. In verband hiermede wordt voorloopig per leerling een deposito gevraagd van $f 50$,- voor leermiddelen.

Het leerarencomité zal zorg dragen de kosten voor leermiddelen tot het strikt noodzakelijke te beperken.

Van dit depositobedrag moet per leerling $f 25,-$ bij de inschrijving worden voldaan, $f 12,50$ bij betaling van den eersten termijn van het cursusgeld, en $f 12,50$ bij betaling van den tweeden termijn van het cursusgeld.

Cursusduur. De cursus duurt ongeveer twee en driekwart jaar.

Diploma. De cursus is in de eerste plaats gericht op het behalen van het Bijzonder Staatsexamen, dat gedurende den duur van den oorlog aan Nederlanders en Nederlandsche onderdanen wordt afgenomen ter vervanging van het in Nederland anders af te leggen eindexamen HBS, afdeeling $\mathrm{B}$. 
Dit noodexamen kan ook te Paramaribo worden afgelegd, echter voor het laatst in den loop van het jaar, waarin de Nederlandsche regeering weer in Nederland terugkeert.

Ingeval daardoor aan het eind van den cursus het officieele examen niet te Paramaribo zou kunnen worden afgelegd, hebben de leerlingen de keus in Nederland het eindexamen HBS af te leggen, of wel in Paramaribo een examen af te leggen, afgenomen door de gezamenlijke leeraren der school. Dit laatste examen zal op hetzelfde peil staan als het Nederlandsche eindexamen HBS B, doch geeft voorloopig niet dezelfde rechten. Het leerarencomité zal echter trachten een oplossing te vinden, waardoor als ons aller hoop op een spoedig einde van den oorlog vervuld zou worden, de leerlingen van dezen cursus toch na afloop van den normalen cursusduur een diploma zouden kunnen verwerven, dat dezelfde rechten geeft als het eindexamen HBS B. Voorloopig kan echter wat dit laatste punt betreft, niets gegarandeerd worden. Wel kan medegedeeld worden, dat reeds een adres aan de Nederlandsche regeering te Londen gericht is, waarin verzocht wordt het noodexamen nog eenigen tijd na de bevrijding van Nederland te laten voortbestaan, terwijl ook de mogelijkheid niet uitgesloten is, dat de cursus recht zou verkrijgen zelf een eindexamen af te nemen, waarvan het diploma de zelfde rechten geeft als het eindexamen HBS B.

Nadere bijzonderheden over het diploma H.B.S. (N i e t o v e rg e nom e n).

Eischen van toelating tot den Cursus. In het algemeen kunnen tot den cursus worden toegelaten leerlingen, in het bezit van het einddiploma van een der MULO-scholen (diploma met wiskunde).

Het leerarencomité zal leerlingen, die bij het eindexamen MULO voor de geëxamineerde vakken een lager gemiddeld cijfer behaalden dan zeseneenhalf $(6,5)$ niet tot den cursus toe laten, voordat door een toelatingsexamen vaststaat, dat zij geschikt zijn voor het volgen van het onderwijs.

Voorbehoud. Het bestuur van de Vereeniging voor Middelbaar Onderwijs in Suriname behoudt zich voor de cursus die 1 November 1944 dient te beginnen, bij onvoldoende deelname niet te laten doorgaan.

Zoodra het maximmumleerlingenaantal dat in een klas wordt toegelaten bereikt is, worden geen nieuwe leerlingen meer toegelaten. 
Leerlingen, die onvoldoende vorderingen maken kunnen van den cursus verwijderd worden, of worden aan het eind van het cursusjaar niet tot de hoogere klasse toegelaten.

Nadere bijzonderheden over de inschrijving van leerlingen. Bij het inleveren van dit inschrijvingsbiljet moeten worden overgelegd:

a. Afschrift van de puntenlijst, betrekking hebbend op het afgelegde Eindexamen MULO, gewaarmerkt door den directeur der school.

$b$. Het definitieve aanslagbiljet in de inkomstenbelasting van ouder of verzorger over het loopende jaar (Alleen ter inzage).

De inschrijvingsbiljetten moeten uiterlijk 30 September a.s. worden ingeleverd.

Degene, wiens besluit vaststaat, wordt verzocht niet tot het laatste te wachten, doch zoo spoedig mogelijk het inschrijvingsbiljet in te leveren, waardoor de voorbereidende werkzaamheden voor den cursus vergemakkelijkt worden.

Tegelijk met de inschrijving moet de eerste termijn van het deposito voor leermiddelen ( $f 25$,- per leerling) gestort worden.

Inschrijvingsbiljetten inleveren en genoemde som voor deposito voor leermiddelen te storten bij Ir. J. E. Heesterman, Prins Hendrikstraat 9, directeur van den cursus.

Verlaten van den Cursus. Indien een leerling den cursus wenscht te verlaten geeft de ouder of verzorger hiervan schriftelijk kennis aan den directeur van den cursus.

Betaling van het cursusgeld is dan nog verplicht over de maand, waarin de kennisgeving wordt ontvangen en de daarop volgende maand.

Nadere inlichtingen. Nadere inlichtingen bij den directeur van den cursus, Ir. J. E. Heesterman, Prins Hendrikstraat 9 en bij Dr. J. F. E. EinaAr, President da Costalaan 2A Voorzitter van de ,Vereeniging voor Middelbaar Onderwijs in Suriname". 